\title{
Polpa Cítrica em Dietas de Vacas em Lactação. 2. Digestibilidade dos Nutrientes em Dois Períodos de Coleta de Fezes, pH e Nitrogênio Amoniacal do Líquido Ruminal ${ }^{1}$
}

\author{
Anderson Jorge de Assis ${ }^{2}$, José Maurício de Souza Campos ${ }^{3}$, Augusto César de Queiroz ${ }^{3}$, \\ Sebastião de Campos Valadares Filho ${ }^{3}$, Ricardo Frederico Euclydes ${ }^{3}$, Rogério de Paula Lana ${ }^{3}$, \\ André Luiz Rodrigues Magalhães ${ }^{2}$, Josué Mendes Neto ${ }^{2}$, Sandro de Souza Mendonça ${ }^{4}$
}

RESUMO - Doze vacas lactantes, da raça Holandesa puras e mestiças, com peso vivo médio inicial de $550 \mathrm{~kg}$, foram distribuídas em três quadrados latinos. O período experimental foi de 18 dias, sete de dias adaptação à dieta e onze dias para coleta de dados. A alimentação fornecida foi para atender os requerimentos de vacas não gestantes produzindo $20 \mathrm{~kg}$ de leite com 4,5\% de gordura, com o objetivo de avaliar a digestibilidade dos nutrientes, esta em dois períodos de coleta de amostra de fezes ( 2 e 5 dias) e no líquido ruminal o pH e nitrogênio amoniacal. A digestibilidade dos nutrientes não foi afetada pelo período de coleta, como também não houve diferença na digestibilidade para os níveis crescentes de polpa cítrica. Não houve diferença significativa $(\mathrm{P}>0,05)$ para pH e nitrogênio amoniacal do rúmen para os diferentes tratamentos. A polpa cítrica pode substituir até $100 \%$ do milho em dietas completas para vacas produzindo em média $20 \mathrm{~kg}$ de leite sem alterar os parâmetros ruminais (pH e amônia amoniacal).

Palavras-chave: alimentação, milho grão, parâmetros ruminais, silagem de sorgo

\section{Citrus Pulp in Diets for Milking Cows. 2. Digestibility of Nutrients in Two Periods of Feces Collection and Rumen Fluid pH and Ammonia Nitrogen}

\begin{abstract}
Twelve milking cows, purebred and crossbred Holstein, with average weight of $550 \mathrm{~kg}$, were allotted to three Latin Squares 4 x 4 . The experimental period lasted 18 days, seven days for the adaptation to the diets and eleven days for data collection. Feeding was supplied to met the requirements of non pregnant cows, producing $20 \mathrm{~kg}$ of milk with $4.5 \%$ fat. The objective of this research was to evaluate the effects of replacement $(0,33,67,100 \%)$ of corn meal by pelleted citrus pulp in the concentrate in total mixed rations, observing the parameters digestibility of the nutrients, and ruminal $\mathrm{pH}$ and ammonia concentration during two periods of collection of sample of feces ( 2 and 5 days). The digestibility of the nutrients were not affected by the collection period, as well as there were not differences in the digestibility for the increasing levels of citrus pulp. No significant differences were observed for $\mathrm{pH}$ and ammonia concentration of the rumen for the different treatments. The citrus pulp can substitute up to $100 \%$ of the corn in complete diets for cows producing $20 \mathrm{~kg}$ of milk in average, without effect on the ruminal parameters ( $\mathrm{pH}$ and ammonia concentration).
\end{abstract}

Key Words: corn meal, feeding, ruminal parameters, sorghun silage

\section{Introdução}

Conforme Van Soest (1994), a digestibilidade e utilização dos nutrientes são uma descrição qualitativa do consumo dos alimentos. Experimentos de digestibilidade com polpa cítrica apresentaram valores de 78 a $92 \%$ para a digestibilidade da matéria seca (MS), 83 a $96 \%$ para a digestibilidade da matéria orgânica (MO) e 40 a $65 \%$ para a digestibilidade da proteína bruta $(\mathrm{PB})$, sendo um alimento de alta digestibilidade, exceto para proteína bruta.

Considerando a alta digestibilidade da polpa cítrica, sugere-se que essa pode substituir fontes de concen- trados energéticos tradicionais como o milho, a cevada e o sorgo e também o volumoso quando se deseja melhoria no consumo e digestibilidade da fibra.

Vários autores relatam que o uso da polpa cítrica na dieta favorece as condições ruminais quando comparada com o uso de concentrados ricos em amido cujo padrão de fermentação diminui o pH ruminal tornando o animal propenso a distúrbios metabólicos e alterações na composição do leite. Leiva et al. (2000), utilizando 11 vacas Holandesas multíparas recebendo dietas contendo 23,6\% de polpa cítrica ou $25,3 \%$ de grão de milho na base matéria seca, não observaram diferença em relação ao $\mathrm{pH}$ ruminal. Resultado semelhante foi encontrado por Rocha

\footnotetext{
${ }^{1}$ Parte da dissertação de Mestrado do primeiro autor apresentada à Universidade Federal de Viçosa, Viçosa - MG.

2 Estudante de Doutorado - Bolsista da CAPES. E.mail: a.j.assis@ibest.com.br

3 Professor do DZO/UFV.

4 Professor do DFZ/UESB.
} 
Filho (1998), ao substituir silagem de milho por polpa cítrica em dieta de vacas fistuladas e não lactantes.

A concentração de amônia pode ser utilizada como indicador da eficiência de sua utilização no rúmen e de uma relação nitrogênio/energia adequada. Altas concentrações de amônia ruminal resultam em maior absorção líquida de nitrogênio amoniacal pelas paredes do rúmen, conversão em uréia e consequentes perdas a partir da excreção urinária. Highfill et al. (1987) observaram que as vacas que receberam polpa cítrica apresentaram maior eficiência de síntese de proteína microbiana. Pinzón \& Wing (1976) observaram que as concentrações de uréia sangüínea e amônia ruminal diminuíram em novilhos alimentados com 19,38 ou $55 \%$ de polpa cítrica.

O período de coleta de fezes deve ter duração suficiente para reduzir ao máximo os erros resultantes da excreção irregular das fezes e da variação diária no comportamento dos animais (Ezequiel et al., 1995). Alguns trabalhos mostraram que a duração do período de coleta depende do nível de nutrição, do tipo de dieta e da espécie animal. Períodos de coleta longos geram maior manipulação do animal, maiores gastos com material para acomodar e preservar as amostras e aumento na mão-de-obra. Portanto, estudos têm sido feitos sobre o tamanho do período de coleta de fezes sem que afete a acuidade das análises feitas nas amostras (Clanton, 1961; Schneider \& Flatt, 1975; Theurer et al., 1981, citados por Ezequiel et al., 1995).

Como o uso de polpa de citrus é recente no Brasil, são poucas as pesquisas sobre os seus benefícios em relação aos aspectos nutricionais, produtivos e econômicos na alimentação de vacas leiteiras nas condições brasileiras.

Assim, tendo em vista a escassez dessas informações na literatura, o presente estudo teve por objetivo avaliar a digestibilidade dos nutrientes em dois períodos de coleta de fezes e os parâmetros ruminais $\mathrm{pH}$ e nitrogênio amoniacal $\left(\mathrm{N}-\mathrm{NH}_{3}\right)$ de vacas recebendo dieta total, à base silagem de sorgo e concentrados, com diferentes níveis de polpa cítrica substituindo o milho em suas composições.

\section{Material e Métodos}

O experimento foi realizado no Setor de Bovinos do Departamento de Zootecnia (DZO), da Universidade Federal de Viçosa (UFV), Viçosa (MG), durante o período de setembro a novembro de 1999.
Foram utilizadas 12 vacas da raça Holandesa Preto e Branco, puras e mestiças, não gestantes, distribuídas em três quadrados latinos, 4 x 4, balanceados.

O experimento foi constituído de quatro períodos com duração de 18 dias cada um, sendo os sete primeiros dias de adaptação e os demais para avaliação da digestibilidade dos nutrientes em dois períodos de coleta de fezes. Os parâmetros ruminais, $\mathrm{pH}$ e nitrogênio amoniacal $\left(\mathrm{N}-\mathrm{NH}_{3}\right)$ foram avaliados num delineamento inteiramente casualizado em parcelas subdivididas.

Os dados obtidos foram submetidos à análise de variância e de regressão ao nível de significância de 5\%, utilizando-se o programa SAEG, versão 7.0 (UFV, 1997). Como tratamento é uma variável contínua (nível de substituição), os graus de liberdade deste efeito foram desdobrados em efeito linear, quadrático e cúbico.

Os animais receberam quatro dietas completas, contendo 0, 33, 67 e 100\% de polpa cítrica em substituição ao fubá de milho. Foram usados no balanceamento das dietas, como alimento concentrado polpa cítrica, fubá de milho, farelo de soja, premix mineral e vitamínico e como volumoso silagem de sorgo. Os ingredientes para formulação do concentrado foram adquiridos, misturados e doados pela empresa Agroceres Nutrição Animal LTDA. A relação volumoso e concentrado, foi de 55:45, base matéria seca. Após análise dos ingredientes disponíveis, as dietas foram formuladas conforme requerimentos do NRC (1989).

A composição dos concentrados e das dietas experimentais, formuladas de acordo com o NRC (1989), é mostrada nas Tabelas 1 e 2.

Periodicamente foram feitas estimativas do teor da matéria seca do volumoso, para ajuste da relação volumoso:concentrado das dietas ao longo dos períodos experimentais.

$\mathrm{Na}$ Tabela 3, encontra-se a composição bromatológica média dos concentrados e da silagem de sorgo utilizada nos quatros períodos experimentais, e na Tabela 4, a composição bromatológica média das dietas experimentais. Observam-se teores crescentes de fibra em detergente neutro (FDN), fibra em detergente ácido (FDA) e lignina (Lig), à medida que o fubá de milho foi substituído pela polpa cítrica. Este fato é explicado em virtude de a polpa cítrica ser mais rica nestas frações em relação ao milho. 
Polpa Cítrica em Dietas de Vacas em Lactação. 2. Digestibilidade dos Nutrientes em Dois Períodos de...

Tabela 1 - Composição percentual dos ingredientes utilizados nos concentrados experimentais (\% na MS)

Table 1 - Percentage composition of the ingredients used in the experimental concentrates (\%DM)

\begin{tabular}{|c|c|c|c|c|}
\hline \multirow[t]{2}{*}{$\begin{array}{l}\text { Ingredientes } \\
\text { Ingredients }\end{array}$} & \multicolumn{4}{|c|}{$\begin{array}{l}\text { Nivel de polpa cítrica (\%) } \\
\text { Citrus pulp level (\%) }\end{array}$} \\
\hline & 0 & 33 & 67 & 100 \\
\hline $\begin{array}{l}\text { Fubá de milho } \\
\text { Corn meal }\end{array}$ & 45,4 & 30,3 & 15,1 & 0,0 \\
\hline $\begin{array}{l}\text { Farelo de soja } \\
\text { Soybean meal }\end{array}$ & 25,6 & 25,6 & 25,6 & 25,6 \\
\hline $\begin{array}{l}\text { Farelo de trigo } \\
\text { Wheat meal }\end{array}$ & 12,2 & 12,2 & 12,2 & 12,2 \\
\hline $\begin{array}{l}\text { Farelo de algodão } \\
\text { Cotton meal }\end{array}$ & 12,2 & 12,2 & 12,2 & 12,2 \\
\hline $\begin{array}{l}\text { Uréia } \\
\text { Urea }\end{array}$ & 1,3 & 1,5 & 1,7 & 1,9 \\
\hline $\begin{array}{l}\text { Fosfato bicálcico } \\
\text { Dicalcium phosphate }\end{array}$ & 1,0 & 1,0 & 1,0 & 1,0 \\
\hline $\begin{array}{l}\text { Calcário calcítico } \\
\text { Limestone }\end{array}$ & 1,0 & 0,8 & 0,6 & 0,4 \\
\hline $\begin{array}{l}\text { Sal mineralizado }{ }^{1} \\
\text { Mineral mix }\end{array}$ & 1,3 & 1,3 & 1,3 & 1,3 \\
\hline
\end{tabular}

Após o parto as vacas foram manejadas em curral coletivo para vacas em início de lactação, recebendo como alimentação silagem de milho à vontade e $1 \mathrm{~kg}$ de concentrado para cada $2,5 \mathrm{~kg}$ de leite produzido em duas refeições diárias (sistema de produção adotado pelo Setor de bovinos do DZO/UFV).

Após atingirem o pico da lactação, as vacas foram transferidas para baias individuais cobertas tipo tie stall, com piso de cimento, contendo comedouros e bebedouros individuais. O piso era limpo todos os dias, quando os animais eram retirados para a ordenha.

As vacas foram ordenhadas mecanicamente, duas vezes ao dia, fazendo-se o registro da produção de leite (PL). A alimentação era fornecida em duas refeições diárias, ad libitum, às 8 e $16 \mathrm{~h}$ após as ordenhas, permitindo-se sobras de até $10 \%$ de matéria seca (MS).

A coleta de fezes foi feita diretamente no reto durante cinco dias consecutivos de manhã e à tarde logo após a ordenha. As amostras foram acondicionadas em sacos plástico devidamente etiquetadas, guardados em congelador e ao final do período de coleta
Tabela 2 - Composição percentual dos ingredientes utilizados nas dietas experimentais (\% na MS)

Table 2 - Percentage composition of the ingredients used in the experimental diets (\%DM)

\begin{tabular}{|c|c|c|c|c|}
\hline \multirow[t]{2}{*}{$\begin{array}{l}\text { Ingredientes } \\
\text { Ingredients }\end{array}$} & \multicolumn{4}{|c|}{$\begin{array}{c}\text { Nivel de polpa cítrica (\%) } \\
\text { Citrus pulp level (\%) }\end{array}$} \\
\hline & 0 & 33 & 67 & 100 \\
\hline $\begin{array}{l}\text { Silagem de sorgo } \\
\text { Sorghun silage }\end{array}$ & 55,00 & 55,00 & 55,00 & 55,00 \\
\hline Polpa cítrica & 0 & 6,80 & 13,63 & 20,43 \\
\hline $\begin{array}{l}\text { Citrus pulp } \\
\text { Fubá de milho } \\
\text { Corn meal }\end{array}$ & 20,43 & 13,63 & 6,80 & 0 \\
\hline $\begin{array}{l}\text { Farelo de soja } \\
\text { Soybean meal }\end{array}$ & 11,50 & 11,50 & 11,50 & 11,50 \\
\hline $\begin{array}{l}\text { Farelo de trigo } \\
\text { Wheat meal }\end{array}$ & 5,50 & 5,50 & 5,50 & 5,50 \\
\hline $\begin{array}{l}\text { Farelo de algodão } \\
\text { Cotton meal }\end{array}$ & 5,50 & 5,50 & 5,50 & 5,50 \\
\hline $\begin{array}{l}\text { Uréia } \\
\text { Urea }\end{array}$ & 0,60 & 0,68 & 0,75 & 0,85 \\
\hline $\begin{array}{l}\text { Fosfato bicálcico } \\
\text { Dicalcium phosphate }\end{array}$ & 0,45 & 0,45 & 0,45 & 0,45 \\
\hline $\begin{array}{l}\text { Calcário calcítico } \\
\text { Limestone }\end{array}$ & 0,44 & 0,36 & 0,29 & 0,19 \\
\hline $\begin{array}{l}\text { Sal mineralizado }{ }^{1} \\
\text { Mineral mix }\end{array}$ & 0,58 & 0,58 & 0,58 & 0,58 \\
\hline
\end{tabular}

${ }^{1}$ Composição percentual (Percent composition): $\mathrm{NaCl}(64,57 \%) ; \mathrm{KCl}$ $(23,07 \%) ; \mathrm{NH}_{3} \mathrm{SO}_{4}$ (7,69\%); $\mathrm{ZnSO}_{4}$ (3,85\%); $\mathrm{CuSO}_{4}$ (0,77\%); $\mathrm{CoSO}_{4}(0,015 \%)$.

foi feita uma amostra composta de cada animal com base no peso seco.

A digestibilidade dos nutrientes foi determinada com dois períodos de coleta de fezes nos últimos cinco dias de cada período experimental. Foram comparados períodos de cinco dias contínuos e dois dias interruptos de coleta de amostra de fezes, sendo este com a primeira coleta no $14^{\circ}$ dia e a segunda coleta no 18 o dia de cada período.

A excreção fecal foi estimada por meio do fornecimento diário de $10 \mathrm{~g}$ de óxido crômico $\left(\mathrm{Cr}_{2} \mathrm{O}_{3}\right)$ pela manhã $(7 \mathrm{~h})$ e $10 \mathrm{~g}$ à tarde $(16 \mathrm{~h})$, durante 10 dias, isto é, cinco dias de adaptação e cinco dias de coleta de fezes, iniciando-se o fornecimento do óxido crômico no oitavo dia após o início de cada período experimental. O teor de cromo nas fezes foi determinado conforme metodologia de Willians et al. (1962).

O líquido ruminal foi coletado de todos os animais, utilizando-se sonda esofágica, segundo Ortolani (1981), para determinação do $\mathrm{pH}$ e da concentração de amônia, nos tempos 0 (antes da alimentação) e 2, 4, e 6 horas após a alimentação matinal do décimo oitavo dia.

Foram coletados aproximadamente $400 \mathrm{~mL}$ de líquido ruminal em recipiente de vidro, em seguida, 
Tabela 3 - Teores médios de matéria seca (MS), matéria orgânica (MO), proteína bruta (PB), extrato etéreo ( $E E)$, carboidratos totais ( $\mathrm{CHO}$ ), fibra em detergente neutro (FDN), carboidratos não fibrosos (CNF), fibra em detergente ácido (FDA) e lignina ( $\mathrm{Lig}$ ) dos concentrados e a silagem de sorgo

Table 3 - Average contents of dry matter (DM), organic matter $(O M)$, crude protein $(C P)$, ether extract $(E E)$, total carbohydrates (CHO), neutral detergent fiber (NDF), nonstructural carbohydrates (NSC), acid detergent fiber (ADF) and lignin (Lig) of the concentrates and sorghun silage

\begin{tabular}{|c|c|c|c|c|c|}
\hline \multirow[t]{2}{*}{$\begin{array}{l}\text { Itens } \\
\text { Items }\end{array}$} & \multicolumn{4}{|c|}{$\begin{array}{c}\text { Nivel de polpa cítrica (\%) } \\
\text { Citrus pulp level (\%) }\end{array}$} & \multirow[t]{2}{*}{$\begin{array}{c}\text { Silagem } \\
\text { Silage }\end{array}$} \\
\hline & 0 & 33 & 67 & 100 & \\
\hline $\begin{array}{l}\text { MS \% } \\
\% D M\end{array}$ & 87,0 & 87,9 & 88,2 & 88,4 & 25,0 \\
\hline $\begin{array}{l}\mathrm{MO}^{1} \\
O M\end{array}$ & 93,4 & 93,3 & 92,4 & 91,7 & 93,4 \\
\hline $\mathrm{PB}^{1}$ & 27,4 & 25,9 & 28,3 & 25,9 & 4,0 \\
\hline $\begin{array}{l}C P \\
\mathrm{EE}^{1}\end{array}$ & 3,5 & 3,2 & 3,0 & 2,7 & 2,3 \\
\hline $\mathrm{CHO}^{1}$ & 63,5 & 65,1 & 62,2 & 63,3 & 86,3 \\
\hline $\begin{array}{l}\mathrm{FDN}^{1} \\
N D F\end{array}$ & 19,1 & 19,5 & 23,2 & 23,3 & 68,1 \\
\hline $\begin{array}{l}\mathrm{CNF}^{1} \\
\mathrm{NSC}\end{array}$ & 44,4 & 45,6 & 39,0 & 40,0 & 18,2 \\
\hline $\mathrm{FDA}^{1}$ & 9,7 & 10,3 & 10,1 & 12,8 & 38,0 \\
\hline $\begin{array}{l}A D F \\
\text { Lig. } 1\end{array}$ & 1,9 & 2,0 & 2,4 & 3,1 & 6,0 \\
\hline
\end{tabular}

1 Porcentagem da MS (DM percentage).

realizou-se a filtragem do mesmo em uma camada de pano, sendo retirada uma alíquota de $40 \mathrm{~mL}$, para cada animal e tempo de coleta, onde foi determinado, imediatamente o $\mathrm{pH}$ por meio de peagâmetro digital. posteriormente adicionou-se $1 \mathrm{~mL}$ de ácido clorídrico a 50\%, sendo então acondicionadas em vidros devidamente identificados, e armazenadas em congelador a $-5^{\circ} \mathrm{C}$ para determinação da concentração de amônia $\left(\mathrm{N}-\mathrm{NH}_{3}\right)$ ruminal.

As análises de MS, MO, compostos nitrogenados totais $(\mathrm{Nt})$, extrato etéreo (EE), FDN, foram feitas segundo Silva (1990). Os carboidratos totais (CHO), carboidratos não fibroso (CNF) e nutrientes digestíveis totais (NDT), foram calculados segundo Sniffen et al. (1992), em que:

$$
\begin{gathered}
\mathrm{CHO}=100-(\% \mathrm{~PB}+\% \mathrm{EE}+\% \mathrm{CINZAS}) ; \\
\mathrm{CNF}=\mathrm{CHO}-\mathrm{FDN}
\end{gathered}
$$$$
\mathrm{NDT}=(\text { PBing }- \text { PBfecal })+(\text { CTing }- \text { CTfecal })+
$$$$
\text { 2,25(EEing - EEfecal), }
$$

em que: PBing $=$ PB ingerida CTing $=\mathrm{CT}$ ingerido $\mathrm{e}$ EEing $=$ EE ingerido.
Tabela 4 - Teores médios de matéria seca (MS), matéria orgânica $(\mathrm{MO})$, proteína bruta (PB), extrato etéreo $(\mathrm{EE})$, carboidratos totais $(\mathrm{CHO})$, fibra em detergente neutro (FDN), carboidratos não fibrosos (CNF), fibra em detergente ácido (FDA), lignina (Lig) e nutrientes digestíveis totais (NDT) obtidos para as dietas experimentais

Table 4 - Average contents of dry matter (DM), organic matter $(O M)$, crude protein $(C P)$, ether extract (EE), total carbohydrates (CHO), neutral detergent fiber (NSF), nonstructural carbohydrates (NSC), acid detergent fiber (ADF), lignin (LIG) and total digestible nutrients (TDN) obtained for the expe-

\begin{tabular}{|c|c|c|c|c|}
\hline \multirow[t]{2}{*}{$\begin{array}{l}\text { Itens } \\
\text { Items }\end{array}$} & \multicolumn{4}{|c|}{$\begin{array}{l}\text { Nivel de polpa cítrica (\%) } \\
\text { Citrus pulp level (\%) }\end{array}$} \\
\hline & 0 & 33 & 67 & 100 \\
\hline MS \% & 52,9 & 53,3 & 53,4 & 53,5 \\
\hline $\begin{array}{l}\% D M \\
M^{1}\end{array}$ & 93,4 & 93,3 & 92,9 & 92,6 \\
\hline $\begin{array}{l}O M \\
\mathrm{~PB}^{1} \\
C P\end{array}$ & 14,5 & 13,8 & 14,9 & 13,8 \\
\hline $\mathrm{EE}^{1}$ & 2,8 & 2,7 & 2,6 & 2,5 \\
\hline $\mathrm{CHO}^{1}$ & 75,6 & 76,3 & 75,0 & 75,5 \\
\hline $\begin{array}{l}\mathrm{FDN}^{1} \\
N D F\end{array}$ & 46,0 & 46,2 & 47,9 & 47,9 \\
\hline $\begin{array}{l}\text { CNF } \\
\text { NSC }\end{array}$ & 29,6 & 30,1 & 27,1 & 27,6 \\
\hline $\begin{array}{l}N S C \\
\text { FDA }^{1} \\
A D F\end{array}$ & 25,2 & 25,5 & 25,4 & 26,6 \\
\hline Lig. ${ }^{1}$ & 4,2 & 4,2 & 4,4 & 4,7 \\
\hline $\mathrm{NDT}^{1}$ & 72,4 & 71,8 & 72,2 & 70,7 \\
\hline$T D N$ & & & & \\
\hline
\end{tabular}
rimental diets

1 Porcentagem da MS (DM percentage).

\section{Resultados e Discussão}

Não houve interação entre período de coleta de amostra de fezes e digestibilidade aparente dos nutrientes e não houve diferença para período de coleta de amostra de fezes (Tabela 5). Estes resultados mostraram que apenas dois dias de coleta foram suficientes para calcular a digestibilidade aparente dos nutrientes sem prejuízo na confiabilidade dos resultados. O mesmo resultado foi encontrado por Ezequiel et al. (1995), em estudo realizado com ovinos, testando 1, 2, 3, 4 e 5 dias de coleta de amostra de fezes. Entretanto, os autores comentam que houve maior confiabilidade dos resultados obtidos com o aumento do tempo de coleta, e que, a partir de três dias os resultados obtidos são adequados em razão da semelhança estatística observada.

As digestibilidades aparentes dos nutrientes não variaram em função da substituição do fubá de milho pela polpa cítrica (Tabela 6). Este resultado pode ser 
Tabela 5 - Digestibilidades aparentes médias de matéria seca (MS), matéria orgânica (MO), proteína bruta (PB), extrato etéreo (EE), carboidratos totais $(\mathrm{CHO})$ e fibra em detergente neutro (FDN), em função do períodos de coleta e suas respectivas médias e coeficiente de variação (CV)

Table 5 - Average apparent digestibilidades of dry matter $(D M)$, organic matter $(O M)$, crude protein $(P B)$, ether extract $(E E)$, total carbohydrats $(C T)$, and neutral detergent fiber (NDF) in function of the collection periods and its respective average and coefficient of variation (CV)

\begin{tabular}{lccccccc}
\hline $\begin{array}{l}\text { Períodos } \\
\text { Periods }\end{array}$ & \multicolumn{7}{c}{$\begin{array}{c}\text { Itens (\%) } \\
\text { Items }\end{array}$} \\
\cline { 2 - 7 } & $\mathrm{MS}$ & $\mathrm{MO}$ & $\mathrm{PB}$ & $\mathrm{EE}$ & $\mathrm{CHO}$ & $\mathrm{FDN}$ & $\mathrm{CV}$ \\
& $D M$ & $O M$ & $C P$ & $E E$ & $C H O$ & $N D F$ & $C V$ \\
\hline 2 dias & 72,1 & 73,1 & 75,9 & 83,0 & 72,0 & 64,6 & 14,37 \\
2 days & 71,9 & 74,5 & 75,8 & 83,9 & 73,8 & 64,0 & 14,43 \\
5 dias & 72,0 & 73,8 & 75,8 & 83,4 & 72,9 & 64,3 & \\
$\begin{array}{l}5 \text { days } \\
\begin{array}{l}\text { Média geral } \\
\text { Average }\end{array}\end{array}$ & 72,0 & & & & & & \\
\hline
\end{tabular}

explicado pela alta degradabilidade da fibra contida na polpa cítrica, impedindo diferenças nas digestibilidades dos nutrientes, quando esta substitui o amido do fubá de milho.

Não houve diferença entre os tratamentos nos diferentes tempos de amostragem e não houve interação tratamento $\mathrm{x}$ tempo de amostragem para níveis de amônia no líquido ruminal, mostrando-se que os diferentes tempos de amostragem influenciaram de maneira igual os tratamentos. As concentrações de amônia do líquido ruminal diferiram em relação aos tempos de amostragem, como mostrado na Figura 1. Uma concentração máxima de amônia do líquido ruminal de $20,5 \mathrm{mg} / 100 \mathrm{~mL}$ foi estimada com o tempo de 3,13 horas após a alimentação.

Os resultados médios encontrados neste estudo foram superiores aos sugeridos por Satter \& Slyter (1974), citados por Leng (1990), de 5 a $8 \mathrm{mg} / 100 \mathrm{~mL}$, para o máximo crescimento microbiano, sendo que em nenhum momento os valores obtidos foram inferiores aos sugeridos por estes autores.

A média dos tratamentos nos vários tempos de amostragem do presente estudo está entre os níveis relatados por Leng (1990), de 10 e $20 \mathrm{mg} / 100 \mathrm{~mL}$, que seriam necessários para promover a máxima digestibilidade e consumo, respectivamente, para forragens de baixo teor de nitrogênio e baixa digestibilidade. Porém, Mehrez et al. (1977) recomendaram que a concentração de amônia que promoveria maior taxa de fermentação seria $23,5 \mathrm{mg} / 100$ $\mathrm{mL}$ de líquido ruminal. Entretanto, este nível de concentração de amônia é praticamente impossível de se manter ao longo do intervalo da alimentação.

Estes resultados estão acima dos encontrados por Rocha Filho (1998), em estudo de substituição de $50 \%$ do milho grão por polpa cítrica, com uma concentração média até as seis horas de $13,9 \mathrm{mg} / 100 \mathrm{~mL}$. Menezes Jr. et al. (2000) também não encontraram diferença na concentração de amônia do líquido

Tabela 6 - Digestibilidades aparentes médias de matéria seca (MS) matéria orgânica (MO), proteína bruta (PB), extrato etéreo (EE), carboidratos totais $(\mathrm{CHO})$ e fibra em detergente neutro (FDN) das dietas experimentais e suas respectivas médias e coeficiente de variação $(C V)$

Table 6 - Average apparent digestibilities of dry matter (DM) organic matter (OM), crude protein (CP), ether extract (EE), total carboidratos (CT) and neutral detergent fiber (NDF) of the experimental diets and its respective average and coefficient of variation (CV)

\begin{tabular}{|c|c|c|c|c|c|c|}
\hline \multirow[t]{2}{*}{$\begin{array}{l}\text { Itens } \\
\text { Items }\end{array}$} & \multicolumn{4}{|c|}{$\begin{array}{l}\text { Nível de polpa cítrica (\%) } \\
\text { Citrus pulp level (\%) }\end{array}$} & \multirow[t]{2}{*}{$\begin{array}{c}\text { Média geral } \\
\text { Average }\end{array}$} & \multirow[t]{2}{*}{$\mathrm{CV}(\%)$} \\
\hline & 0 & 33 & 67 & 100 & & \\
\hline $\begin{array}{l}\text { MS } \\
D M\end{array}$ & 72,84 & 72,72 & 72,22 & 71,85 & $Y=72,41$ & 4,91 \\
\hline $\begin{array}{l}\text { MO } \\
\text { OM }\end{array}$ & 73,01 & 75,01 & 73,44 & 74,27 & $Y=73,93$ & 4,54 \\
\hline $\begin{array}{l}\mathrm{PB} \\
C P\end{array}$ & 75,05 & 76,98 & 75,45 & 76,37 & $Y=75,96$ & 4,84 \\
\hline $\begin{array}{l}\mathrm{EE} \\
E E\end{array}$ & 83,92 & 81,93 & 85,34 & 81,60 & $Y=83,20$ & 5,21 \\
\hline $\begin{array}{l}\mathrm{CHO} \\
\mathrm{CHO}\end{array}$ & 72,07 & 74,29 & 72,47 & 73,48 & $Y=73,08$ & 4,92 \\
\hline $\begin{array}{l}\text { FDN } \\
N D F\end{array}$ & 66,76 & 63,32 & 65,32 & 64,84 & $Y=65,06$ & 6,80 \\
\hline
\end{tabular}




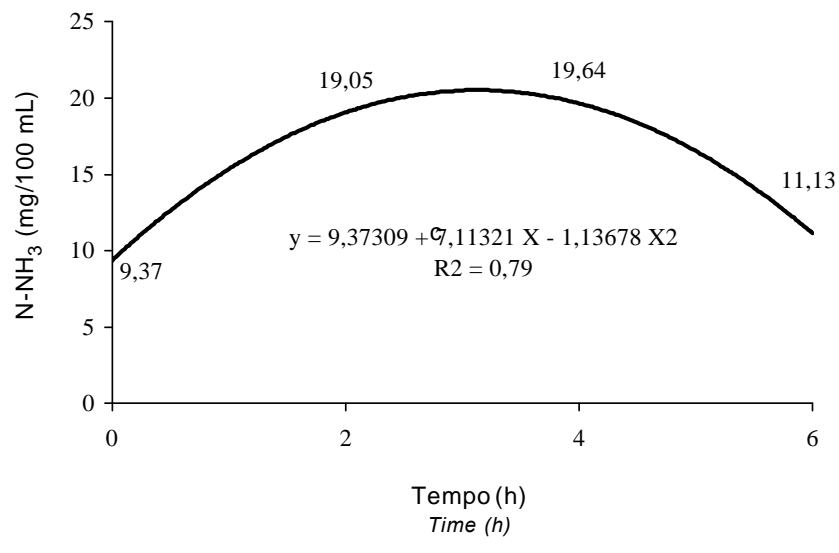

Figura 1 - Concentrações de amônia no líquido ruminal, em $\mathrm{mg} / 100 \mathrm{~mL}$, obtidos nos tempos $(\mathrm{T})$ : antes da alimentação (0) e 2, 4 e 6 horas após a alimentação e sua equação de regressão.

Figure 1 - Amônia concentrations in the rumen fluid, in $\mathrm{mg} / 100 \mathrm{~mL}$, obtained in the times $(T)$ before feeding (0) and 2, 4 and 6 hours post feeding and its regression equation.

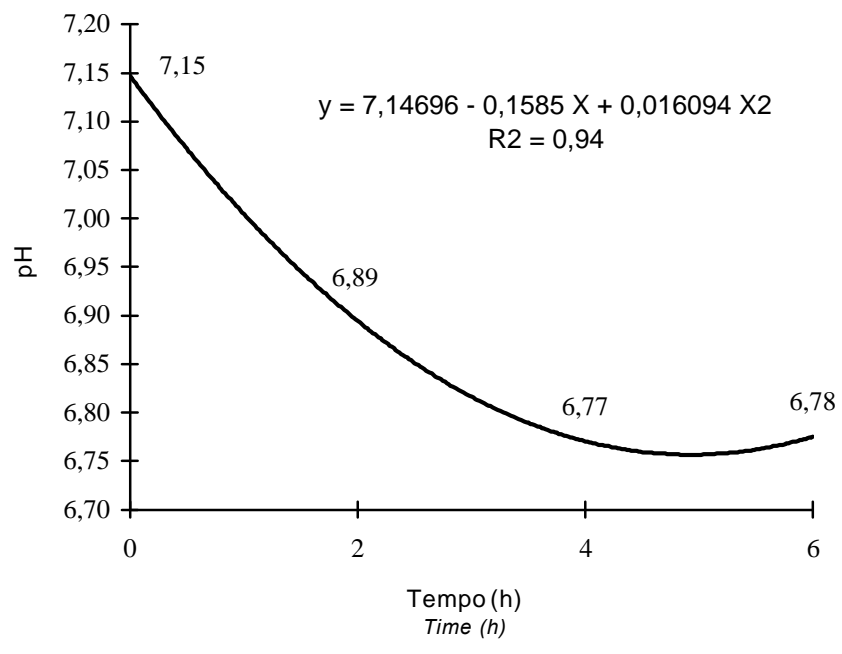

Figura 2 - Equação de regressão ajustada e valores médios de $\mathrm{pH}$ do líquido ruminal obtidos nos tempos (T) antes da alimentação (0) e 2, 4 e 6 horas após a alimentação.

Figure 2 - Equation of adjusted regression and average value of $\mathrm{pH}$ of the rumen fluid obtained in the times $(T)$ before feeding (0) and 2, 4 and 6 hours after feeding.

ruminal quanto à inclusão de polpa cítrica na dieta.

Os valores do $\mathrm{pH}$ do líquido ruminal, obtidos para os tratamentos nos diferentes tempos de amostragem, são apresentados na Figura 2. Observa-se que não houve diferença dos tratamentos sobre o $\mathrm{pH}$ do líquido ruminal nos diferentes tempos de amostragem, mostrando-se que a diferença ocorreu apenas em função do tempo, independentemente das dietas experimentais, em virtude do intenso processo de fermentação e, conseqüentemente, da maior produção de ácidos graxos voláteis após a alimentação. Valor mínimo de $\mathrm{pH}$ de 6,76 foi estimado com 4,92 horas após a alimentação.

Os resultados médios encontrados neste estudo estão acima aos encontrados por Rocha Filho (1998), utilizando vacas fistuladas para determinar o efeito da polpa cítrica na substituição da silagem de milho nos níveis de 0,25 e $40 \%$ e na substituição do milho em $50 \%$. Os valores médios até às seis horas foram 6,40 e 6,24 para a substituição da silagem de milho e do milho. As baixas relações volumoso : concentrado utilizadas pelo autor $(39,3: 60,7$ e 28,4:71,6, respectivamente) podem ter contribuído para a diminuição do $\mathrm{pH}$.

\section{Conclusões}

O milho grão pode ser substituído em $100 \%$ por polpa cítrica peletizada em rações concentradas, para vacas produzindo, em média, $20 \mathrm{~kg}$ de leite, sem alterar a digestibilidade aparente dos nutrientes, como também, a substituição do milho pela polpa cítrica não afetou os parâmetros ruminais, $\mathrm{pH}$ e concentração de amônia.

O período de coleta de fezes para estimativa da digestibilidade aparente pode ser diminuído para dois dias sem afetar a confiabilidade dos resultados.

\section{Agradecimento}

À Universidade Federal de Viçosa; ao Departamento de Zootecnia da UFV; e à empresa Agroceres Nutrição Animal, pelo apoio.

\section{Literatura Citada}

CLANTON, D.C. Comparison of 7 and 10 day collection periods in digestion and metabolism trials with beef heifers. Journal of Animal Science, v.20, p.640, 1961.

EZEQUIEL, J.M.B.; SAMPAIO, A.A.M.; OLIVEIRA, M.D.S. Efeito do período de coleta sobre a digestibilidade de alguns nutrientes, em ensaios com ovinos. Revista da Sociedade Brasileira de Zootecnia, v.24, n.2, p.261-269, 1995.

HIGHFILL, B.D.; BOGS, D.; AMOS, H.E.; CRICKMAN, J.G. Effects of high fiber energy supplements on fermetation characteristics and in vivo and in situ digestibilities of low quality fescue hay. Journal of Animal Science, v.65, p.224-234, 1987. 
LEIVA, E.; HALL, M.B.; Van HORN, H.H. Performance of dairy cattle fed citrus pulp or corn products as sources of neutral detergent - soluble carbohydrates. Journal of Dairy Science, v.83, n.12, p.2866-2875, 2000.

LENG, R.A. Factors affecting the utilization of "poor-quality" forages by ruminants particularly under tropical conditions. Nutrition Research Reviews, v.3, p.277-303, 1990.

MEHREZ, A.Z.; ORSKOV, E.R.; McDONALD I. Rates of rumen fermentation in relation to ammonia concentration. British Journal Nutrition, v.38, p.437-443, 1977.

MENEZES JR., M.P.; SANTOS, F.A.P.; GUIDI, M.T. et al. Processamento do grão de milho e sua substituição parcial por polpa de citros sobre os Itens ruminais e composição do leite de vacas holandesas. In: REUNIÃO DA SOCIEDADE BRASILEIRA DE ZOOTECNIA, 37., 2000, Viçosa, MG. Anais... Viçosa, MG: Sociedade Brasileira de Zootecnia, 2000.

NATIONAL RESEARCH COUNCIL - NRC. Nutrient requirements of dairy cattle. 6.ed. Washington, D.C.: National Academy Press, 1989. 157p.

ORTOLONI, E.L. Considerações técnicas sobre o uso da sonda esofágica na colheita do suco de rúmen de bovinos para mensuração do pH. Arquivo da Escola de Veterinária da Universidade Federal de Minas Gerais, v.33, n.2, p.269-275, 1981.

PINZON, F.J.; WING, J.M. Effects of citrus pulp in high urea rations for steers. Journal of Dairy Science, v.59, p.1100-1103, 1976.

ROCHA FILHO, R.R. Efeitos da polpa de citrus e do milho sobre Itens ruminais. Piracicaba: Escola Superior de Agricultura Luiz de Queiroz, 1998. 71p. Dissertação (Mestrado em Agronomia) - Universidade de São Paulo, 1998.
SILVA, D.J. Análise de alimentos: métodos químicos e biológicos. Viçosa, MG: Universidade Federal de Viçosa, 1990. 165p.

SNIFFEN, C.J.; O'CONNOR, J.D.; Van SOEST, P.J. et al. A net carbohydrate and protein system for evaluating cattle diets; II. Carbohydrate and protein availability. Journal of Animal Science, v.70, n.11, p.3562-3577, 1992.

STAPLES, G.E.; DINUSSON, N.E. A comparison of the relative collection between seven-day and ten-day collection periods in digestion trials. Journal of Animal Science, v.10, p.244, 1951.

UNIVERSIDADE FEDERAL DE VIÇOSA - UFV. SAEG Sistema de Análises Estatísticas e Genéticas. Viçosa, MG, 1997 (Versão 7.0).

Van SOEST, P.J. Nutritional ecology of the ruminant. Ithaca: Cornell University Press, 1994. 476p.

WILLIANS, C.H.; DAVID, D.J.; IILMA, O. The determination of cromic oxide in faeces samples by atomic absorption spectrophotometry. Journal of Agricultural Science, v.59, p.381-385, 1962.

Recebido em: 17/06/02

Aceito em: 03/02/03 